УДК 316

$10.17213 / 2075-2067-2020-5-42-52$

\title{
РОЛЬ СЕМЬИ В СОЦИАЛИЗАЦИИ ИНВАЛИДОВ (ПО РЕЗУЛЬТАТАМ ЭМПИРИЧЕСКОГО ИССЛЕДОВАНИЯ)
}

\author{
(C) 2020 г. Л. С. Деточенко
}

\section{Южный федеральный университет, г. Ростов-на-Дону, Россия}

Цель исследования - на основе ретроспективных нарративов молодых людей с инвалидностью изучить роль сочиальной адаптации семьи, наличия сочиальной поддержки, типа внутрисемейных отношений, степени деформации семейных функций на социализаичию инвалидов.

Методологическая база исследования. Теоретико-методологическая база исследования основана на синтезе подходов. Конструктивистский подход (П. Бергер., Т. Лукман, А. Шюи, Е. Ярская-Смирнова, Р. Скотт) акиентирует внимание на изучении инвалидности как социального конструкта, порождаемого спецификой сочиальных отношений. Институционализм позволяет понять повседневные практики стигматизации в условиях изменения социальной политики, перехода от медицинской к социальной модели инвалидности, трансформации основных институтов и акторов, отвечающих за сочиализацию инвалидов, формирование новых типов поведения индивидов и их идентичности (Д. Марч, К. Скинник, Й. Олсен).

Результаты исследования. Данные нарративов позволяют говорить о преобладании негативных моделей социальной адаптаџии, узости сочииальной поддержки, значительной деформации семейных функиий в российских семьях, воспитывающих детей с инвалидностью. Зафиксирован негативный опыт переживания стигмы и факт жестокого обращения в семье как следствия воспроизводства практик стигматизачии в повседневной жизни. Определено значение семьи в опыте осознания факта заболевания и его социальных последствий. Проанализированы условия положительного влияния многопоколенной модели семьи и сиблинговых связей на результаты сочиализации молодого инвалида.

Перспективу исследования составляет дальнейший социологический анализ факторов сочуиальной адаптаџии семьи с особым ребенком, построения сетей сочуиальной поддержки.

Ключевые слова: сочиализаџия инвалидов; семья, воспитывающая ребенка-инвалида; нарратив.

\section{THE ROLE OF THE FAMILY IN THE SOCIALIZATION OF DISABLED PEOPLE (BASED ON THE RESULTS OF AN EMPIRICAL STUDY)}

\section{(C) 2020 L. S. Detochenko}

\section{Southern Federal University, Rostov-on-Don, Russia}

The purpose of the study is to study the role of social adaptation of families, the availability of social support, the type of intra-family relationships, and the degree of deformation of family functions on the socialization of disabled people based on retrospective narratives of young people with disabilities. 
The methodological base of the research. The theoretical and methodological basis of the research is based on the synthesis of approaches. The constructivist approach (P. Berger, T. Lukman, A. Schutz, E. Yarskaya-Smirnova, R. Scott) focuses on the study of disability as a social construct generated by the specifics of social relations. Institutionalism makes it possible to understand the everyday practices of stigmatization in the context of changing social policy towards people with disabilities, the transition from a medical to a social model of disability, the transformation of the main institutions and actors responsible for the socialization of people with disabilities, the formation of new types of behavior of individuals and their identity (D. March, K. Skinnick, J. Olsen).

The results of the study. These narratives allow us to speak about the prevalence of negative models of social adaptation, narrowness of social support, and significant deformation of family functions in Russian families raising children with disabilities. Negative experiences of stigma and abuse in the family were recorded as a consequence of the reproduction of stigmatization practices in the daily life of the family. The importance of the family in the experience of understanding the fact of the disease and its social consequences is determined. The conditions of positive influence of the multi-generational family model and sibling connections on the results of socialization of a young disabled person are analyzed.

The prospect of the study. Further sociological analysis of the factors of social adaptation of a family with a special child and the construction of social support networks is the perspective of the research.

Key words: socialization of persons with disabilities; family caring for a child with a disability; narrative.

Введение. Актуальность исследования влияния семьи на результаты социализации инвалида обусловлена несколькими причинами. Численность семей, воспитывающих детей с инвалидностью, увеличивается, в том числе и в Российской Федерации. Так за последние 4 года количество детей-инвалидов в возрасте до 18 лет возросло в нашей стране на 81 тысячу человек (590 тысяч человек на 1.01.2015 г;; 671 тысяча человек на 1.01.2019 г. [1]).

Изменение социальной политики в отношении инвалидов, ратификация целого ряда фундаментальных международных правовых актов, направленных на защиту прав инвалидов, привели к изменению ожиданий общества от семьи, воспитывающей особого ребенка. Основная задача семьи трансформировалась от ухода и обеспечения элементарных функций к формированию необходимых условий для успешной интеграции инвалида в общество. Между тем социокультурные традиции России, общий уровень инклюзивной культуры, многочисленные социальные барьеры препятствуют расширению социальной поддержки семьи и создают реальную угрозу множественных отклонений от социализационной нормы. Вместо того чтобы стать главным проводником социальных изменений, семья часто воспроизводит традиционные стигматизирующие практики. Исследование процесса и закономерностей социального конструирования инвалидности должно начинаться в семье. Модели социализации, формирование ценностей, эталонов и норм социализации детерминированы социумом. Главным агентом их трансляции выступает именно семья. В условиях наличия как инновационных практик социальной адаптации, так и традиционных дискриминирующих практик, именно от позиции семьи зависит социализационная траектория инвалида.

Семья, в структуру которой входит ребенок-инвалид, может представлять двойной исследовательский интерес для социологии семьи. С одной стороны, воспитание инвалида изменяет функционирование семьи как социального института и малой группы. Трансформируются структура и функции семьи, брачно-семейные отношения, моде- 
ли семейного жизнеустройства и образцы семейного поведения. С другой стороны, характер и степень изменений влияют на социализацию самого инвалида. Рефлексия характера семейных отношений, роли семьи в собственном жизненном пути, осмысление места семейных ценностей в собственной иерархии ценностей, принятие или отвержение «пролонгации» семейной опеки предопределяют важнейшие характеристики социализационной траектории молодых инвалидов: скорость протекания, вектор определения дальнейшего пути развития и результативность социализационного процесса на выходе из отроческого возраста. Особую актуальность имеет взгляд самих молодых инвалидов на особенности сложившихся семейных отношений и роль семьи в собственной жизни, ее места в перспективных планах социализационного развития. В научном дискурсе изучение роли семьи в социализации инвалидов имеет ряд особенностей. Признание важным значения семьи в жизни инвалида является своеобразной аксиомой для исследователей. Однако, анализ эмпирических исследований показывает ряд противоречий и парадоксов. Большинство из них посвящено влиянию воспитания особого ребенка на саму семью и ее членов (супругов, сиблингов). Основными темами здесь выступают: копинг-стратегии или адаптационные стратегии семей к сложившимся условиям $[2,3,4]$, трансформация семейных функций $[5,6]$, качество жизни и благополучие семьи и ее членов $[7,8,9]$. Влияние же конкретной модели семьи, транслируемых ею повседневных практик, внутрисемейных отношений на результаты социализации самого инвалида стали лишь недавно входить в круг исследовательских интересов $[10,11,12]$. Еще одной особенностью является «отсутствие» голоса самих инвалидов. Между тем личное участие инвалидов в объективной оценке услуг, освещении собственной жизнедеятельности и исследованиях закреплено в фундаментальных международных нормативно-правовых актах (Всемирной программе действий в отношении инвалидов [13], Конвенции о правах инвалидов [14]). Жизнедеятельность семьи изучается на основе экспертного мнения профессионального сообщества или на основе представления родителей. Таким образом, существует явное противоречие между актуальностью исследования роли семьи в социализации молодых инвалидов и широтой и глубиной научных наработок в данной области. Исследование же взгляда самих молодых инвалидов на роль собственной семьи в социализации и осмысление ее роли в системе ценностей и перспективных планов развития, к сожалению, не встречалось автором. В связи с этим целью данной статьи является изучение роли социальной адаптации семьи, наличия социальной поддержки, типа внутрисемейных отношений, степени деформации семейных функций на социализацию молодых людей с инвалидностью.

Методы исследования. Представленные в данной статье результаты исследования являются одним из аспектов изучения процесса особого взросления, проведенного в 2019 году. В данной статье представлены данные о роли семьи в социализации инвалида, выборе социальной траектории его развития, успешности его адаптации в социум. Прослеживая социализационные траектории респондентов в нарративах, мы стремились подчеркнуть важнейшие для становления личности инвалида события семейного процесса и маркеры социального климата. В качестве метода исследования нами был выбран метод нарративного анализа. Основным посылом автобиографических тематических нарративов являлся ответ на просьбу рассказать историю своего взросления. Всего за 2019 год было получено 30 нарративов. При формировании выборки использовалась стратегия снежного кома, при этом в качестве значимых параметров рассказчиков автором исследования обозначались: пол, возраст (от 16 до 35 лет), нозология (репрезентация патологий опорно-двигательного аппарата, зрения, слуха, речи), место проживания и обучения (выпускники и обучающиеся специализированных школ-интернатов и инклюзивных образовательных учреждений).

\section{Столкновение с диагнозом и его осоз-} нание. Травма, заболевание приобретают значение тогда, когда человек осознает его социальные последствия, реальное значение для своей повседневной жизни, возможные последствия для будущих планов. Среди рес- 
пондентов были как инвалиды детства, так и те, кто столкнулся с медицинским диагнозом в более взрослом возрасте. Рождение ребенка с инвалидностью - исключительное и неожиданное событие, которое тяжело переживается всеми членами семьи, требует времени для адаптации. К моменту осознанного возраста ребенка семья зачастую уже преодолевает первый стресс от понимания диагноза, поэтому в нарративах респондентов мы не находим травмирующих переживаний первого шока семьи, столкнувшейся с фактом тяжелого недуга ребенка. В то же время именно приобретение заболевания/получения травмы становится отправной точкой нарратива второй категории респондентов, столкнувшихся с инвалидностью в более позднем возрасте. Болезнь/травма становится экзистенциальной точкой, «разрывающей» нарратив. Нарративы, повествующие о получении травмы, детализированы. Сила воздействия нового факта бытия настолько сильна, что подавляет все события и переживания. Реакция семьи (шок, отрицание, страдание, депрессия) всегда представлены в описании переломного события жизни. Типовые сюжеты основного повествования данного тематического поля включают: рассказы о сложности постановки диагноза, поиска качественной медицинской помощи, психологического стресса от формализованного отношения персонала к информированию о диагнозе, сложности организации быта, режима дня, жизнедеятельности семьи в новых условиях, адаптации к собственному телу и состоянию здоровья, непонимание социальных и медицинских аспектов последствий диагноза. Одним из важнейших и часто встречающихся сюжетов является изменение внутрисемейных взаимоотношений, супружеских отношений в данный период. От того, насколько быстро семья принимает ситуацию и выработает свой собственный адаптационный механизм, зависит скорость адаптации ребенка/молодого человека к новому состоянию здоровья и условиям жизнедеятельности. Наоборот, низкие адаптационные способности семьи, затягивающийся внутрисемейный кризис являются одним из факторов замедленных социализационых процессов молодых инвалидов.

В случае с инвалидами детства ряд нарративов дают воспоминания о первом осоз- нании факта особого состояния своего здоровья. Зачастую именно члены семьи становятся первым источником информирования ребенка о диагнозе, его течении.

«Я помню себя маленькой девочкой, которая очень сильно испугалась от того, что у неё заболевание, о котором начали разговаривать окружаюшие люди. Потом мне стало немножко страшно, что я воспринимаю себя не такой, как все, что у меня не будет такой же свадьбы, как у всех, что у меня не будет такой же семьи, об этом начали говорить окруюающие меня люди» (И. 6, Ж., 31 год, инвалид детства).

Подчас последствия медицинских диагнозов непонятны, недостаток информации не позволяет представить объективно собственное состояние здоровья. Тогда именно реакция семьи является «лакмусовой бумажкой», определяющей степень проблемы и ее возможные последствия для жизни. Анализ нарративов позволяет говорить о том, что реакция семьи на диагноз и форма информирования ребенка о состоянии здоровья играют большое значение в социализации инвалида. Неприятие, отторжение, внутрисемейная стигматизация не только являются болезненным социально-психологическим опытом для личности ребенка, но и служат основой формирования самостигматизации, негативно сказывающейся на всем процессе социализации.

Социальная адаптация семьи. Результаты исследования позволяют говорить о том, что адаптация семей к необходимости круглосуточной помощи и постоянному сопровождению больного ребенка происходит разными способами.

Одним из таких вариантов является обрашенние родителей к традиционному распределению семейных ролей. Такая модель соответствует традициям и ожиданиям российского общества. На отца возлагаются обязанности по экономическому обеспечению семьи, на мать же - обязанности «сохранения домашнего очага», воспитания и реабилитации. Ответственность за ребенка-инвалида полностью возлагается на мать. Следует отметить, что такое распределение семейных обязанностей является негативным фактором, повышающим угрозу семейного бла- 
гополучия, неудовлетворенности семейной жизни [15]. Мать является центральным персонажем нарратива, который во многом определяет модель поведения молодого человека и уровень его притязаний.

В такой модели мать становится безусловным лидером, определяющим траектории развития своего ребенка. Диктаторское решение матери может «пролонгировать» детство, отодвигая возраст перехода к взрослому состоянию. Гиперопека матери в сочетании с доминирующей ролью в жизни семьи и ребенка часто становятся непреодолимым барьером в получении профессионального образования, включении в сообщества, профессиональной самореализации. Несмотря на взросление, переход к отрочеству, а потом и к молодому взрасту, инвалид обладает малой свободой самостоятельности и выбора. Все решения, в том числе и значимые для дальнейшего роста и самосовершенствования, единолично принимает мать. Именно мать чаще всего транслирует такую модель взаимодействия, которая закрепляет за ребенком «роль больного» (Т. Парсонс).

Такая модель внутрисемейного социального взаимодействия ведет к формированию высокой степени зависимости от семьи, порой отожествляемой с самой возможностью дальнейшей жизни.

Чаще всего в такой семье полностью отсутствуют или слабо развиты навыки альтернативных социальных взаимодействий (дружеские связи, включенность в клубную, общественную работу, местное сообщество и др.). В молодом возрасте семейная изоляция перерастает в самоизоляцию, негативизм, низкий уровень самооценки. Уход в творческую или учебную деятельность не приносит значимых результатов, поскольку сочетается с низкими коммуникативными навыками и заниженным уровнем притязаний. Формируются невротические черты в виде страхов, агрессии и т.д.

Делегчрование полномочий профессиональному сообществу помогающих профессий. Социальная роль женщины предполагает заботу и жертвенность матери, готовность отдать все свободное время ребенку. Однако, по мере роста ребенка установки самих родителей и ожидания общества требуют уменьшения объема участия родителя в жиз- ни ребенка. Круглосуточный уход за ребенком в раннем детстве социально приемлем, в то время как сохранение высокой вовлеченности в ежедневные практики ухода с ростом ребенка воспринимаются обществом и родителями иначе. Это приводит к поиску форм временного делегирования ответственности за ребенка. Такой формой выступают специализированные школы-интернаты. В нарративах инвалидов, возраст которых превышает 30 лет, часто присутствует тема школы-интерната. Среди положительных аспектов обучения в данном учреждении можно назвать: приобретение самостоятельности (большинство школ такого типа — интернатного), расширение взаимодействия с референтными группами (до обучения коммуникативное пространство ребенка зачастую ограничивается кругом семьи), основательную базу для адаптационного и общего образования, широкие возможности для вовлечения обучающихся в различные формы досуга (клубную работу, адаптированные спортивные секции). Между тем именно биографы, обучавшиеся в специализированных образовательных учреждениях, являются носителями стигматизированной идентичности, которая оказывает большое значение на построение всей последующей жизненной траектории.

С 2000 г. в социальную сферу активно входят новые субъекты (Фонды, НКО), практики (ранняя интервенция, временный уход). Указанные изменения происходят как раз в период жизнедеятельности наших респондентов, однако ни в одном нарративе мы не нашли инновационных практик помощи семье. Среди возможных причин такие ситуации: географическая неравномерность оказываемой помощи и явные диспропорции в оказании сопровождения молодых людей с инвалидностью в противовес детям-инвалидам. Таким образом, единственным вариантом получить помощь и высвободить время для родителей до сих пор остается система специализированных учреждений.

Другим вариантом адаптации к повседневным обязанностям ухода за больным ребенком является возложение ответственности за уход на более старших членов семьи. В этом случае роль матери в нарративе замещает бабушка. Родители в такой модели берут на себя ответственность воспитания 
других детей и финансовое обеспечение реабилитационного процесса.

«Росла без родителей. Бабушка и дедушка меня забрали в трехлетнем возрасте. Родители отказались. У них я была нелегально. ... Отношения с родителями не складывались. По большей части общение сводилось к приходам на праздники. В основном занималась мной бабушка. Дедушка редко мной занимался» (И 10, Ж., 27 лет, 1 группа).

В том же случае, когда ребенок-инвалид отрывается от родителей и своих братьев и сестер, а коммуникация с ним сводится к минимуму, мы видим глубокий травмирующий след в нарративе.

Между тем основные нарративы, повествующие о совместном проживании (многопоколенная семья), позволяют говорить не только о положительном влиянии на благополучие семьи, но и в целом на социализацию ребенка с инвалидностью.

Сиблинги (отношение с братьями и сестрами). Ранняя литература по исследованию последствий совместного воспитания ребенка-инвалида и нормативных братьев и сестер фиксировала внимание на негативных аспектах данного опыта [16]. Ученые отмечали негативные последствия вовлечения братьев и сестер в обязанности по уходу за ребенком $[17,18]$ или снижение родительского внимания к детям за счет необходимости уделять больше времени больному ребенку [19]. Со временем появились исследования, отмечающие и положительные аспекты воспитания нормативных и особых детей как для нормативных сиблингов (снижение агрессии, гиперактивности, лучшее воспитание [20]), так и для социализации самих инвалидов. В поиске истины неоценимы ретроспективные нарративы инвалидов, которые позволяют познакомиться с рефлексией отношений с братьями и сестрами в горизонтальной плоскости. Анализ нарративов показал как позитивный, так и негативный опыт взаимодействия между кровными братьями и сестрами в семье с инвалидом.

«И отнотения с родственниками. Не было их вообще. С сестрой мы не общались. Ну как, если я позвоню, то мы общались, если нет, то мне месяцуами не звонили» (И. 10, 27 лет, 1 группа).
«Мы с братом съехали. Сейчас вместе живем. Брат работает. Я с ним. ... Он всегда был со мной» (И. 25, М., 24 года, 2 группа).

«Дед работал. Имя рос своей жизнью. Имя - это младший сын моей бабушки. Я чувствую себя виноватым перед ним. Бабушка им вообще не занималась из-за меня» (И. 10, Ж., 27 лет, 1 группа).

Следует отметить, что на характер взаимоотношений между сиблингами влияет позиция родителей, модель воспитания. Там, где в нарративе запечатлен болезненный, травмирующий опыт детско-родительских отношений, там присутствует и негативный опыт взаимодействия с братьями и сестрами. Отношение между братьями и сестрами носят изменчивый характер и зависят от возраста. Кризисный период отмечен в нарративах, связанных с подростковым возрастом: «Я стала чувствовать, что она меня стесняется. Просто отрезала меня от своих друзей» (И. 29 лет, Ж., 31 год, 1 группа).

Наличие братьев и сестер при условии «нормальных взаимоотношений» можно считать мощнейшим ресурсом социальной адаптации и нормализации жизнедеятельности. Именно посредством братьев и сестер возможно преодолеть коммуникативные барьеры и сложности, расширить социальные контакты и событийность повседневной жизни.

Внешняя социальная поддержка семьи. К внешней социальной поддержке возможно отнести поддержку родственников, друзей, родительских групп поддержки.

Анализ нарративов не представил нам данных о позитивной роли внешней поддержки семьи со стороны родственников. Однако, есть примеры, фиксирующие негативный опыт взаимодействия.

«Я никогда не ошущзала со стороны родственников такое, чтобы они воспринимали меня, как часть семьи. ... Всем говорят: "У тебя будет семья, ты выйдешь замуж, дети", а мне такого не говорят... И это меня очень сильно обижало, всегда... И все это, опять же, я сваливала на заболевание» (И 6, Ж., 31 год, инвалид детства).

Взаимодействие семьи с окружающим социумом, местным сообществом скудное, что существенно сужает круг общения самого ребенка. Стигматизирующие практики по- 
буждают к резкому ограничению социальных контактов, изоляции, разрыву социальных связей, «поддержание социального капитала семьи и тем более, его накопление становится затруднительным» (П. Бурдье [21], Дж. Коулман [22]).

«По сути, я долго не общзался ни с кем, кроме своей семьи» (И. 8, инвалид детства 1 группы, 19 лет).

Маркеры семейного микроклимата. Супружеские взаимоотношения и детскородительские отношения. Анализ нарративов показывает, что сложности, с которыми сталкивается семья, часто приводят к ее распаду. Интересно, что в этом случае в воспоминаниях интервьюера есть и образы матери, и образы отца, факт развода зачастую замалчивается, только уточняющие вопросы позволяют установить распад супружеских отношений. Между тем сохранение семьи и благоприятного микроклимата в ней является важным источником поддержки инвалида в детском, отроческом возрасте и на этапе перехода к зрелости. Семья поддерживает ребенка в борьбе за свое здоровье («Осложнения. Мама была со мной. С мамой было намного легче лежать в больнице» (И 8, М., 19 лет, инвалид детства 1 группы)); в формировании жизненных целей и их реализации («Каждый день родители со мной занимались. Ставили иели. Ходил в специализированный интернат. A вот иколь такой не было. Родителям пришлось переехать, чтобы я образование получил. По совету мамы, я поступил в институт на дефектологию» (И 15, М. 34 года,1 группа инвалидности)); в нормализации социализационной траектории («Я думаю, что такого результата бы не было, если бы родители c самого раннего рождения не вложились в мое развитие. Я помню, как родителям предложили отправить меня в специальную и коррекционную школу, но они отказались. Я ходила в общую школу» (И. 12. Ж., 29 лет, 1 группа инвалидности)). Супружеские отношения запечатлены в нарративах, в основном, в негативном формате: недопонимание, неравномерное распределение ролей, депрессия и усталость родителей. При характеристике детско-родительских отношений образ матери встречается повсеместно. Бо- лее редки воспоминания об отце. Следует отметить, что образ отца и его роль в жизни ребенка-инвалида более актуализируется при переходе от отрочества к зрелости. Отец здесь - источник финансовых ресурсов обеспечения развития, он - источник помощи в преодолении гиперопеки.

Деформация семейных функций. Появление ребенка-инвалида в семье приводит к деформации не только образа жизни, но и семейных функций. Социализация ребенка уходит на второй план.

«Меня скорее лечили, чем растили и воспитыввали. Упор был на то, чтобы я скорее выжила, изначально. А то, как оно дальше будет, никто не знал, и такими вопросами никто не задавался» (И 10, Ж., 27 лет, 1 группа инвалидности).

Для родителей детей-инвалидов характерен экстернальный родительский контроль болезни, когда причины болезни воспринимаются как нечто, не зависящее от родителей, также для них свойственна гипернозогнозия (преувеличение тяжести болезни ребенка). Такое отношение к заболеванию ребенка определяет значительное напряжение, характерное для данных родителей и их взаимоотношений с ребенком. Происходит концентрация на соматическом состоянии ребенка (часто в ущерб его эмоциональному и личностному развитию).

«У бабушки страхи были, я везде была только с ней. Никакой сочиализации у меня не было». (И 10, Ж., 27 лет, 1 группа).

Негативные переживания. Стигматизация в семье. Жестокое обращение. Целый ряд основных нарративов содержал сюжеты внутрисемейной стигматизации. «Тяжело жить было, и найти врачей было достаточно сложно, я это понимаю, но, опять же, сейчас у меня до сих пор какое-то не такое, может быть, осуждение $\kappa$ родителям, что да, вы бы попытались еше бы больше поискать, почему я сльишала в основном в свой адрес осуждающие реплики, что я не такая, как все; такое ощущение, что мы как будто дикое общество, а не развитые люди, как будто вот у меня складывалось впечатление, что мы как-то живем не так, как все» (И 6, 31 год, инвалид детства). 
Выделяют несколько схем действий родителей на рождение ребенка, имеющего проблемы со здоровьем:

— принятие ребенка и его дефекта - родители принимают дефект, адекватно оценивают его и проявляют по отношению к ребенку настоящую преданность;

- реакция отрицания - отрицают, что ребенок имеет дефект. Планы относительно образования и профессии ребенка свидетельствуют о том, что родители не принимают и не признают для своего ребенка никаких ограничений;

- реакция чрезмерной защиты, протекции и опеки. Родители наполнены чувством жалости и сочувствия, что проявляется в чрезмерно заботливом и защищающем ребенка от всех опасностей типе воспитания;

- скрытое отречение, отвержение ребенка. Дефект считается позором. Отрицательное отношение и отвращение к ребенку скрывается за чрезмерно заботливым предупредительным воспитанием;

- открытое отречение, отвержение ребенка. Ребенок принимается с отвращением, и родители полностью осознают свои враждебные чувства $[23,4,23]$. «Тяжелье отношения у меня были с отиом: он периодически проявлял ко мне насилие, да, поднимал руку, причём это продолжалось до лет 15 где-то» (И 6, Ж., 31 год, инвалид детства).

Заключение. В целом проведенный анализ ретроспективных нарративов позволяет сделать ряд выводов.

1. Социолингвистический анализ текстового массива позволяет говорить о принципиальном различии в протекании социализационного процесса у инвалидов детства и инвалидов, получивших травму или заболевание в более позднем (осознанном) возрасте.

2. Столкновение с ограничением по здоровью как социальным ограничением - важнейший травмирующий опыт, успешное преодоление которого является необходимым условием нормальной социализации.

3. Данные нарративов позволяют говорить о преобладании негативных моделей социальной адаптации, узости социальной поддержки, значительной деформации семейных функций в российских семьях, воспитывающих детей с инвалидностью.
4. Наличие братьев и сестер может служить как мощнейшим ресурсом социальной интеграции и адаптации, преодоления коммуникативной дезадаптации, так и болезненным и травмирующим фактором внутрисемейной стигматизации. Характер сиблинговых отношений, скорее, связан с моделью семьи, типом детско-родительских отношений (родитель - ребенок-инвалид), чем с характером и сложностью заболевания.

5. Многопоколенная модель положительно влияет не только на благополучие семьи, но и на социализацию ребенка-инвалида. Возложение ответственности за уходом за детьми-инвалидами на более старших членов семьи с отчуждением ребенка от родителей и других братьев и сестер, раздельным проживанием увеличивает риски социализации и оставляет глубокий травмирующий след.

6. Несмотря на декларируемые изменения в социальных практиках помощи семье, воспитывающей ребенка-инвалида, инновационные практики (временный уход, ранняя семейная интервенция, помощь волонтеров, профессионального сообщества помогающих профессий (социальные работники, реабилитологи и др.)) остаются недостаточно развитыми. Единственным вариантом снижения нагрузки на семью является обращение к специализированным учреждениям, транслирующим практики старой модели социализации инвалидов.

7. Имеют место быть факты жестокого обращения в семье и негативный опыт переживания стигмы внутри семьи как пережитки старой модели социального взаимодействия.

\section{Литература}

1. Распределение инвалидов по полу и возрасту. [Электронный ресурс] // Федеральная служба государственной статистики. - Режим доступа: https:// www.gks.ru/folder/13964 (Дата обращения: 15.04.2020).

2. Heaman D.J. Perceived Stressors and Coping Strategies of Parents who have children with Developmental Disabilities: A comparison of Mother with Father// Journal of Pediatric Nursing. - 1995. - Vol. 10. — №5 (October). - P. 311-320. 
3. Carlson J.M., Miller P.A. Family burden, child disability, and the adjustment of mothers caring for children with epilepsy: Role of social support and coping // Epilepsy \& Behavior. 2017. - Vol. 68 (March). - P. 168-173.

4. Ying Zhang, Min Wei, Nanping Shen, Yaqing Zhang. Identifying Factors Related to Family Management During the Coping Process of Families with Childhood Chronic Conditions: A Multi-Site Study // Journal of Pediatric Nursing. — 2015. - Vol. 30. — №1 (January-February). - P. 160-173.

5. Benito Lara E., C. Carpio de los Pinos. Families with a Disabled Member: Impact and Family Education // Procedia. - Social and Behavioral Sciences. - 2017. - Vol. 23721 (February). - P. 418-425.

6. Crowell J.A., Keluskar J., GoreckiA. Parenting behavior and the development of children with autism spectrum disorder // Comprehensive Psychiatry. — 2019. - Vol. 90 (April). - P. 21-29.

7. Joana M., Mas C., Dunst J., Balcells-Balcells A., Garcia-Ventura S., C. Giné, Cañadas M. Family-centered practices and the parental wellbeing of youngchildren with disabilities and developmental delay // Research in Developmental Disabilities. - 2019. - Vol. 94. — №103495 (November). - P. 1-13.

8. Siti Nor Ismalina Isa, Ismarulyusda Ishak, Azriani Ab Rahman, Nur Zakiah Mohd Saat, Muhammad Faiz Mohd Ismail. Health and quality of life among the caregivers of children with disabilities: A review of literature // Asian Journal of Psychiatry. - 2016. - Vol. 23 (October). - P. 71-77.

9. Dzamonja Ignjatovic T., Milanovic M., Zegarac $N$. How services for children with disabilities in Serbia affect the quality of life of their families // Research in Developmental Disabilities. - 2017. - Vol. 68 (September). - P. 1-8.

10. Heyman M., Hauser-Cram P. The influence of the family environment on adaptive functioning in the classroom: A longitudinal study of children with developmental disabilities// Research in Developmental Disabilities. 2019. - Vol. 86 (March). - P. 20-30.

11. Di Marino E., Tremblay S., Khetani M., Anaby $D$. The effect of child, family and environmental factors on the participation of young children with disabilities // Disability and Health Journal. — 2017. — Vol. 11 (Jan). — P. 36-42.
12. Taylor Dyches T., Smith T.B., Korth B.B., Olsen Roper $S$., Mandleco B. Positive parenting of children with developmental disabilities: A meta-analysis // Research in Developmental Disabilities. - 2012. - Vol. 33. — №6 (NovemberDecember). - P. 2213-2220.

13. Всемирная программа действий в отношении инвалидов. Принята резолюцией 37/52 Генеральной ассамблеей от 3 декабря 1982 года [Электронный ресурс] // Официальный сайт ООН. - Режим доступа: https://www. un.org/ru/documents/decl_conv/conventions/ prog3.shtml (Дата обращения: 15.04.2020).

14. Конвенция о правах инвалидов Принята резолюцией 61/106 Генеральной Ассамблеи от 13 декабря 2006 года. [Электронный ресурс] - Режим доступа: https://www. un.org/ru/documents/decl_conv/conventions/ disability.shtml (Дата обращения: 15.04.2020).

15. Kathleen Ell. Social networks, social support and coping with serious illness: The family connection // Social Science \& Medicine. 1996. - Vol. 42. - №2 (January). - P. 173-183.

16. Gath A. The impact of an abnormal child upon the parents. // The Br J Psychiatry. 1977. - Vol. 130. — №4 (April). - P. 405-410.

17. Lobato D., Faust D., Spirito A. Examining the effects of chronic disease and disability on children's sibling relationship. // J Pediatr Psychol. - 1988. - Vol. 13. - P. 389-407.

18. Nelson M., Ruch S., Jackson Z., et al. Towards an understanding of families with physically disabled adolescents // Soc Work Health Care. - 1992. - Vol. 17. - P. 1-25.

19. Neuer N., Strom G.A. Guidance and support for parents. In: Kiernan W.E., Morrison P., eds. Comprehensive management of cerebral palsy. New York: Grune \& Stratton, 1983. - P. 293-297.

20. Dyson L.L. Adjustment of siblings of handicapped children: a comparison // Pediatr Psychol. - 1989. - Vol. 25. - P. 459-76.

21. Bourdie P. The forms of capital // Handbook of Theory and Research for the Sociology of Education / Ed. by J. G. Richardson. - N. Y.: Greenwood Press., 1986. - P. 241-258.

22. Коулман Дж. Капитал социальный и человеческий // Общественные науки и современность. - 2001. - №3. - С. 122-139.

23. Ткачева В.В. О некоторых проблемах семей, воспитывающих детей с отклонениями в развитии // Дефектология. - 1998. №4. - С. 17-26. 


\section{References}

1. Raspredelenie invalidov po polu i vozrastu [The distribution of disabled persons by sex and age]. [Jelektronnyj resurs] // Federal'naja sluzhba gosudarstvennoj statistiki [Federal state statistics service]. — URL: https://www.gks.ru/ folder/13964 (Date accessed: 15.04.2020).

2. Heaman D.J. Perceived Stressors and Coping Strategies of Parents who have children with Developmental Disabilities: A comparison of Mother with Father// Journal of Pediatric Nursing. - 1995. - Vol. 10. — №5 (October). - Pp. 311-320.

3. Carlson J.M., Miller P.A. Family burden, child disability, and the adjustment of mothers caring for children with epilepsy: Role of social support and coping // Epilepsy \& Behavior. 2017. - Vol. 68 (March). - Pp. 168-173.

4. Ying Zhang, Min Wei, Nanping Shen, Yaqing Zhang. Identifying Factors Related to Family Management During the Coping Process of Families with Childhood Chronic Conditions: A Multi-Site Study // Journal of Pediatric Nursing. — 2015. - Vol. 30. — №1 (January-February). - Pp. 160-173.

5. Benito Lara E., C. Carpio de los Pinos. Families with a Disabled Member: Impact and Family Education // Procedia. - Social and Behavioral Sciences. - 2017. — Vol. 23721 (February). - Pp. 418-425.

6. Crowell J.A., Keluskar J., Gorecki A. Parenting behavior and the development of children with autism spectrum disorder // Comprehensive Psychiatry. - 2019. - Vol. 90 (April). - P. 21-29.

7. Joana M., Mas C., Dunst J., Balcells-Balcells A., Garcia-Ventura S., C. Giné, Cañadas M. Family-centered practices and the parental wellbeing of youngchildren with disabilities and developmental delay // Research in Developmental Disabilities. - 2019. — Vol. 94. — №103495 (November). - Pp. 1-13.

8. Siti Nor Ismalina Isa, Ismarulyusda Ishak, Azriani Ab Rahman, Nur Zakiah Mohd Saat, Muhammad Faiz Mohd Ismail. Health and quality of life among the caregivers of children with disabilities: A review of literature // Asian Journal of Psychiatry. — 2016. — Vol. 23 (October). - Pp. 71-77.

9. Dzamonja Ignjatovic T., Milanovic M., Zegarac N. How services for children with dis- abilities in Serbia affect the quality of life of their families // Research in Developmental Disabilities. - 2017. — Vol. 68 (September). - Pp. 1-8.

10. Heyman M., Hauser-Cram P. The influence of the family environment on adaptive functioning in the classroom: A longitudinal study of children with developmental disabilities// Research in Developmental Disabilities. 2019. - Vol. 86 (March). - Pp. 20-30.

11. Di Marino E., Tremblay S., Khetani M., Anaby $D$. The effect of child, family and environmental factors on the participation of young children with disabilities // Disability and Health Journal. — 2017. — Vol. 11 (Jan). Pp. 36-42.

12. Taylor Dyches T., Smith T.B., Korth B. B., Olsen Roper S., Mandleco B. Positive parenting of children with developmental disabilities: A meta-analysis // Research in Developmental Disabilities. - 2012. - Vol. 33. — №6 (November-December). — Pp. 2213-2220.

13. Vsemirnaja programma dejstvij v otnoshenii invalidov. Prinjata rezoljuciej 37/52 General'noj assambleej ot 3 dekabrja 1982 goda [The world programme of action concerning disabled persons. Adopted by the General Assembly resolution 37/52 of December 3, 1982] [Jelektronnyj resurs] // Oficial'nyj sajt OON. URL: https://www.un.org/ru/documents/decl conv/conventions/prog3.shtml (Date accessed: 15.04.2020).

14. Konvencija o pravah invalidov Prinjata rezoljuciej 61/106 General'noj Assamblei ot 13 dekabrja 2006 goda [The Convention on the rights of persons with disabilities was Adopted by General Assembly resolution 61/106 of 13 December 2006]. [Jelektronnyj resurs] — URL: https://www.un.org/ru/documents/decl conv/ conventions/disability.shtml (Date accessed: 15.04.2020).

15. Kathleen Ell. Social networks, social support and coping with serious illness: The family connection // Social Science \& Medicine. - 1996. - Vol. 42. — №2 (January). Pp. 173-183.

16. Gath A. The impact of an abnormal child upon the parents. // The Br J Psychiatry. 1977. - Vol. 130. — №4 (April). — Pp. 405-410.

17. Lobato D., Faust D., Spirito A. Examining the effects of chronic disease and disability on children's sibling relationship. // J Pediatr Psychol. - 1988. - Vol. 13. - Pp. 389-407. 
18. Nelson M., Ruch S., Jackson Z., et al. Towards an understanding of families with physically disabled adolescents // Soc Work Health Care. - 1992. - Vol. 17. - Pp. 1-25.

19. Neuer N., Strom G. A. Guidance and support for parents. In: Kiernan W.E., Morrison P., eds. Comprehensive management of cerebral palsy. - New York: Grune \& Stratton, 1983. Pp. 293-297.

20. Dyson L.L. Adjustment of siblings of handicapped children: a comparison // Pediatr Psychol. - 1989. - Vol. 25. - Pp. 459-76.

21. Bourdie P. The forms of capital // Handbook of Theory and Research for the Sociology of Education / Ed. by J. G. Richardson. - N. Y.: Greenwood Press., 1986. - Pp. 241-258.

22. Koulman Dzh. Kapital social'nyj i chelovecheskij [Social and human capital] // Obshhestvennye nauki i sovremennost' [Social Sciences and modernity]. — 2001. - №3. Pp. 122-139.

23. Tkacheva V.V. O nekotoryh problemah semej, vospityvajushhih detej s otklonenijami v razvitii [On some problems of families raising children with developmental disabilities] // Defektologija [Defectology]. — 1998. — №4. Pp. 17-26.

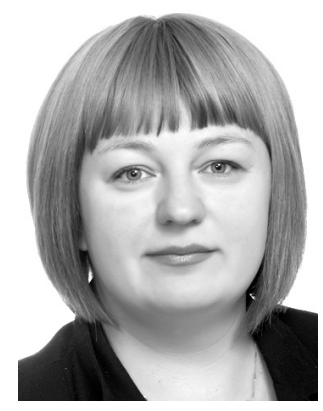

Деточенко Людмила Станиславовна - кандидат философских наук, доцент, заведующая кафедрой социальных технологий Института философии и социально-политических наук Южного федерального университета. Основные сферы исследуемой проблематики: проблемы социализации молодежи, развитие инклюзивных практик в России, социализационные траектории молодежи с особыми потребностями.

Detochenko Ludmila Stanislavovna - Candidate of Philosophical Sciences, Head of the Department of Social Technologies, Institute of Philosophy and Socio-political Sciences, Southern Federal University. The main areas of research: problems of youth socialization, development of inclusive practices in Russia, socialization trajectories of young people with special needs.

346500, г. Шахты, ул. Красный Шахтер, 19

19 Krasny Shakhter st., 346500, Shakhty, Russia

E-mail: maksimus6488@yandex.ru 